\title{
Estudio bioquímico del veneno de la anémona de mar Phymactis papillosa (Actiniidae)
}

\author{
Biochemical study of venom sea anemone Phymactis papillosa (Actiniidae)
}

\section{Antony Cuya y Enrique Escobar*}

Laboratorio de Bioquímica de Toxinas Naturales. Facultad de Ciencias Biológicas. Universidad Nacional Mayor de San Marcos.

*Autor para correspondencia

Email Enrique Escobar: eescobarg@unmsm.edu.pe

Email Antony Cuya: antony.cuya@unmsm.edu.pe

\section{Resumen}

En este trabajo se ha estudiado bioquímicamente el veneno de Phymactis papillosa, colectadas en la bahía de Ancón. El veneno fue obtenido mediante shock hipotónico y luego se liofilizó. El análisis electroforético del veneno soluble mostró la presencia de 5 bandas proteicas con pesos moleculares entre 5 y 25.1 kDa.

El veneno soluble fue fraccionado por cromatografía de filtración en una columna de Sephadex G-50, obteniéndose cuatro picos de proteína (I, II, III y IV). Tanto en el veneno soluble como en las fracciones colectadas se midió actividad de proteasa, fosfolipasa, hialuronidasa, fosfatasa ácida y fosfatasa alcalina; así como, actividad hemolítica y neurotóxica. Se encontró actividad proteolítica sobre caseína, en el veneno soluble y en los picos I y III. No se detectó actividad de fosfolipasa, hialuronidasa, fosfatasa ácida y fosfatasa alcalina. La actividad hemolítica, ensayada sobre eritrocitos humanos, se encontró en el veneno soluble y en el pico II. Finalmente, tanto el veneno soluble como el pico III mostraron ser neurotóxicos al ser inyectados en ratones albinos vía intraperitoneal. Se concluye que el veneno soluble de $P$. papillosa tiene actividad proteolítica, hemolítica y neurotóxica.

Palabras clave: veneno; anémona de mar; toxinas; neurotoxinas.

\section{Abstract}

In this work, the poison of Phymactis papillosa collected in Ancón bay has been studied biochemically. The venom was obtained by hypotonic shock and then lyophilized. Electrophoretic analysis of the soluble poison showed the presence of 5 protein bands with molecular weights between 5 and $25.1 \mathrm{kDa}$. The soluble venom was fractionated by filtration chromatography on a Sephadex G-50 column, yielding four protein peaks (I, II, III and IV). In the soluble venom and collected fractions was measured protease activity, phospholipase, hyaluronidase, acid phosphatase and alkaline phosphatase; as well as hemolytic and neurotoxic activity. Proteolytic activity on casein was found in the soluble venom and peaks I and III. Was not detected phospholipase activity, hyaluronidase, acid phosphatase and alkaline phosphatase. Hemolytic activity on human red cells tested, was found in the soluble venom and peak II. Finally, the soluble venom as the peak III showed be neurotoxic when injected into white mice intraperitoneally. It is concluded that the soluble venom of $P$. papillosa has proteolytic, hemolytic and neurotoxic activity.

Keywords: poison; sea anemone; toxins; neurotoxins.

Citación:

Cuya A. \& E. Escobar. 2017. Estudio bioquímico del veneno de la anémona de mar Phymactis papillosa (Actiniidae). Revista peruana de biología 24(3): 303 - 310 (octubre 2017). doi: http://dx.doi.org/10.15381/ rpb.v24i3.13901

Información sobre los autores:

AC, EE: realizaron el diseño experimental, los experimentos, analizaron los datos, redactaron y aprobaron el manuscrito.

Los autores no incurren en conflictos de intereses. $\begin{array}{ll}\text { Presentado: } & 21 / 12 / 2016 \\ \text { Aceptado: } & 13 / 06 / 2017\end{array}$

Publicado online: $28 / 10 / 2017$ 


\section{Introducción}

El estudio bioquímico de los venenos de anémonas de mar ha mostrado que contienen, principalmente, componentes proteicos que funcionan como enzimas, hemolisinas, neurotoxinas o inhibidores de proteasa (Frazao et al. 2012). Entre las enzimas de estos venenos, se han encontrado enzimas proteolíticas y lipolíticas. Así por ejemplo, en el veneno de Anthothoe chilensis se han reportado fracciones proteicas con actividad proteolítica y actividad de fosfolipasa (Retuerto et al. 2007, Landucci et al. 2012), y del veneno de Aiptasia pallida se ha purificado y caracterizado una fosfolipasa (Grotendorst \& Hessinger, 1999).

En relación a las hemolisinas, las cuales también se denominan actinoporinas, éstas se caracterizan por formar poros de aproximadamente $1 \mathrm{~nm}$ de radio en las membranas celulares, lo cual provoca que la célula pierda el control del intercambio de fluidos con el ambiente y muera (Crnigoj et al. 2009). Gran parte del interés en estudiar estas proteínas, es encontrar actinoporinas que formen poros específicamente en las membranas de células cancerosas y puedan destruirlas (Jouiaei et al. 2015).

Otro de los componentes característicos de los venenos de anémonas de mar lo constituyen las neurotoxinas, que son péptidos que afectan el funcionamiento de los canales iónicos de sodio y de potasio de las membranas celulares de neuronas y células musculares, y cuyo bloqueo daña el sistema nervioso central (Jouiaei et al. 2015). Éstos péptidos, por su especificidad, pueden ser utilizados en estudios de estructura y función de canales iónicos.

En el Perú solamente el veneno de Anthothoe chilensis ha sido estudiado parcialmente (Retuerto et al. 2007, Landucci et al. 2012, Quiroz 2005), y no se tiene información sobre investigaciones de venenos en otras especies de anemonas. En este trabajo se informa de las caracteristicas del veneno de Phymactis papillosa (Lesson, 1830).

\section{Material y métodos}

Anémonas de mar.- Siete ejemplares de Phymactis papillosa (Lesson, 1830) var. rubra-viridis (Haussermann 2004) se colectaron en la orilla rocosa de la playa San Francisco en Ancón, Lima, Perú. Los ejemplares colectados fueron colocados en frascos de vidrio con agua de mar y trasladados inmediatamente al laboratorio.

Ratones albinos.- Se utilizaron ejemplares de Mus musculus de 20 a 22 g. de peso, que fueron comprados en el Instituto de Medicina Tropical de la Universidad Nacional Mayor de San Marcos, el mismo día de los ensayos de toxicidad. Con los ratones se procedió de acuerdo con la Guía de manejo y cuidado de animales de laboratorio: ratón, del Instituto Nacional de Salud de Lima (Fuentes et al. 2008); y la "ley de protección a los animales domésticos y a los animales silvestres mantenidos en cautiverio" (Ley 27265).

Extracción del veneno.- El veneno se obtuvo por shock hipotónico, para lo cual 7 ejemplares de P.papillosa se colocaron en un beaker con $30 \mathrm{~mL}$ de agua destilada durante 60 minutos (Fig. 1). Luego el material fue filtrado en papel whatman y posteriormente centrifugado a $12000 \mathrm{rpm}$ por 30 minutos. El sobrenadante fue liofilizado.

Preparación del veneno.- El veneno liofilizado $(67 \mathrm{mg})$ fue disuelto en $1 \mathrm{~mL}$ de buffer acetato de amonio $0.05 \mathrm{M} \mathrm{pH} 7$ y los restos insolubles fueron separados por centrifugación a 12000 rpm durante 20 minutos.

Cuantificación de proteínas.- Para estimar la cantidad de proteína en el veneno soluble y en las fracciones obtenidas durante la separación cromatográfica, se midió la absorbancia de luz ultravioleta a $280 \mathrm{~nm}$ (Warburg \& Christian 1941).

Electroforesis en gel de poliacrilamida con dodecil sulfato de sodio (PAGE-SDS).- El perfil electroforético del veneno soluble de $P$. papillosa se determinó en condiciones denaturantes, de acuerdo al método de Schägger \& von Jagow (1987), utilizando como proteínas estándares una mezcla de fragmentos de mioglobina (16950, 14440, 10600, 8160 y 6210 Da) y glucagón (3480 Da).

Para determinar la actividad proteolítica del veneno soluble y de las fracciones cromatográficas colectadas, también se utilizó electroforesis en condiciones denaturantes, pero según el método de Laemmli (1970).

Separación de las proteínas del veneno por cromatografía de filtración.- Los componentes del veneno fueron separados por cromatografía de filtración molecular, para lo cual se aplicó $0.75 \mathrm{~mL}$ de veneno $67 \mathrm{mg} / \mathrm{mL}$ a una columna de Sephadex G-50 $(1.1 \times 56.6 \mathrm{~cm})$ calibrada con buffer acetato de amonio $0.05 \mathrm{M}$ $\mathrm{pH} 7$ y a un flujo de $5 \mathrm{~mL} / \mathrm{h}$. Se colectaron 70 fracciones de 1 $\mathrm{mL}$ y en cada una se leyó la absorbancia a $280 \mathrm{~nm}$.

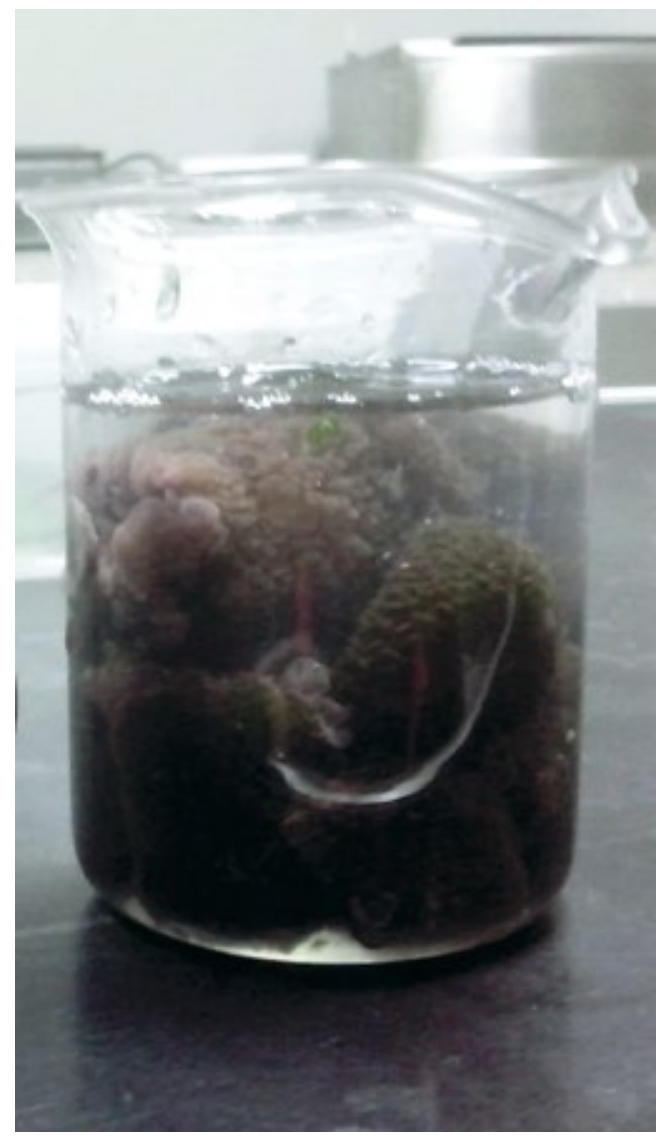

Figura 1. Extracción del veneno de Phymactis papillosa var. rubra-viridis por shock hipotónico. Siete ejemplares de $P$. papillosa fueron colocados en $30 \mathrm{~mL}$ de agua destilada durante 1 hora. Este cambio osmótico produce la liberación del veneno de los nematocistos. 
Actividad proteolítica sobre caseína.- La actividad proteolítica en el veneno soluble y las fracciones colectadas fue ensayada sobre caseína mezclando $5 \mu \mathrm{L}$ de caseína $20 \mathrm{mg} / \mathrm{mL}$ preparada en buffer Tris $0.05 \mathrm{M} \mathrm{pH} \mathrm{8,} \mathrm{y} 20 \mu \mathrm{L}$ del veneno $4 \mathrm{mg} / \mathrm{mL}$ o de las fracciones colectadas. Luego de incubar a $37^{\circ} \mathrm{C}$ por 60 minutos, la hidrólisis de la caseína fue evaluada por electroforesis en gel de poliacrilamida con dodecil sulfato de sodio (PAGE-SDS), de acuerdo al método de Laemmli (1970).

Actividad proteolítica sobre fibrinógeno.- Solo en el veneno soluble se ensayó la actividad proteolítica sobre fibrinógeno. La mezcla de reacción contenía $5 \mu \mathrm{L}$ de fibrinógeno $10 \mathrm{mg} / \mathrm{mL}$ preparado en buffer Tris $0.05 \mathrm{M} \mathrm{pH} 7.5$ y $20 \mu \mathrm{L}$ del veneno $5 \mathrm{mg} /$ $\mathrm{mL} \mathrm{pH} \mathrm{7,} \mathrm{que} \mathrm{fueron} \mathrm{incubados} \mathrm{a} 37^{\circ} \mathrm{C}$ por 30 minutos, luego de lo cual la actividad proteolítica se determinó por PAGE-SDS.

Adicionalmente se evaluó el efecto del EDTA sobre el veneno en su actividad proteolítica sobre fibrinógeno. Se preincubó 20 $\mu \mathrm{L}$ del veneno $5 \mathrm{mg} / \mathrm{mL} \mathrm{pH} 7$ con $4 \mu \mathrm{L}$ de EDTA $30 \mathrm{mM}$ a $37^{\circ} \mathrm{C}$ por 10 minutos y luego se ensayó la actividad proteolítica sobre fibrinógeno, tal como se describió anteriormente.

Actividad de fosfatasa.- La mezcla de reacción contenía 0.2 $\mathrm{mL}$ de p nitro fenil fosfato $20 \mathrm{mM}, 0.275 \mathrm{~mL}$ de buffer acetato de sodio $0.01 \mathrm{M} \mathrm{pH} 4.8$ (para detectar fosfatasa ácida) o buffer tris $0.05 \mathrm{M} \mathrm{pH} 8$ (para detectar fosfatasa alcalina) y $25 \mu \mathrm{L}$ del veneno $4 \mathrm{mg} / \mathrm{mL}$ o de las fracciones colectadas. Se incubó a $37^{\circ} \mathrm{C}$ durante 30 minutos y la reacción fue detenida con $1 \mathrm{~mL}$ de $\mathrm{NaOH} 0.2 \mathrm{M}$, para luego leer a $410 \mathrm{~nm}$ el p nitro fenol liberado.

Actividad de hialuronidasa.- Fue determinada de acuerdo al método de Di Ferrante (1956). La mezcla de reacción contenía $0.1 \mathrm{~mL}$ de ácido hialurónico $0.5 \mathrm{mg} / \mathrm{mL}$ preparado en buffer acetato de sodio $0.1 \mathrm{M} \mathrm{pH} \mathrm{5,} \mathrm{y} 20 \mu \mathrm{L}$ del veneno $4 \mathrm{mg} / \mathrm{mL}$ o de las fracciones colectadas. Se incubó a $37^{\circ} \mathrm{C}$ durante 15 minutos y la reacción fue detenida con $1.4 \mathrm{~mL}$ de CTAB (bromuro de cetil trimetil amonio) $2.5 \%$, para luego leer la absorbancia a $400 \mathrm{~nm}$.

Actividad de fosfolipasa.- La actividad de fosfolipasa se evaluó por el método de Marinetti (1965). La mezcla de reacción contenía $1 \mathrm{~mL}$ de una emulsión de yema de huevo en buffer tris $0.05 \mathrm{M}$ pH $8(\mathrm{~A} 920=0.8)$ y $100 \mu \mathrm{L}$ del veneno $4 \mathrm{mg} / \mathrm{mL}$ o de las fracciones colectadas. Se midió la absorbancia a $920 \mathrm{~nm}$ cada minuto y durante 5 minutos.
Actividad hemolítica.- Fue evaluada por el método de Torres-Larios et al. (2000). La mezcla de reacción contenía 0.1 $\mathrm{mL}$ de eritrocitos humanos $5 \%, 0.88 \mathrm{~mL}$ de buffer tris $0.05 \mathrm{M}$ $\mathrm{NaCl} 0.15 \mathrm{M} \mathrm{pH} 7.5$ y $20 \mu \mathrm{L}$ del veneno $4 \mathrm{mg} / \mathrm{mL}$ o de las fracciones colectadas. Se incubó a $37^{\circ} \mathrm{C}$ durante 10 minutos y se centrifugó a $6000 \mathrm{rpm}$ por 10 minutos. Luego el sobrenadante fue leído a $541 \mathrm{~nm}$ para medir la hemoglobina liberada.

Toxicidad sobre Mus musculus.- Se inyectó en ratones albinos (Mus musculus), vía intraperitoneal, $100 \mu \mathrm{L}$ de veneno $4 \mathrm{mg} / \mathrm{mL}$ o de las fracciones colectadas. La toxicidad sobre el sistema nervioso se evaluó por la aparición de síntomas como salivación, convulsiones, parálisis del tren posterior y muerte.

\section{Resultados}

Extracción del veneno.- La extracción de veneno mediante shock hipotónico, a partir de 7 ejemplares, permitió obtener 67 mg de veneno liofilizado.

Contenido proteico.- Según el método de Warburg \& Christian, se determinó que el veneno de $P$. papillosa contiene $18.85 \%$ de proteína. Es decir los $67 \mathrm{mg}$ de veneno obtenido contienen $9.47 \mathrm{mg}$ de proteína.

Separación de las proteínas del veneno por cromatografía de filtración.- Luego de pasar $0.75 \mathrm{~mL}$ del veneno liofilizado a una concentración de $67 \mathrm{mg} / \mathrm{mL}$ (9.47 mg de proteína) por la columna de filtración molecular de Sephadex G-50, y determinar la absorbancia a $280 \mathrm{~nm}$ de cada fracción colectada, se obtuvo un perfil cromatográfico con 4 picos proteicos, tal como se muestra en la Figura 2.

Electroforesis en gel de poliacrilamida con dodecil sulfato de sodio (PAGE-SDS).- La PAGE-SDS (Schagger \& Von Jagow 1987) del veneno soluble de $P$. papillosa mostró la presencia de 5 bandas proteicas con pesos moleculares de 25.1, 21.6, 12.4, 7.5 y $5.0 \mathrm{kDa}$, siendo la primera y la última banda las de mayor intensidad, tal como se observa en la Figura 3.

Actividad proteolítica sobre caseína.- La actividad proteolítica sobre caseína se detectó tanto en el veneno soluble como en las fracciones cromatográficas de los picos I y III. El veneno soluble produjo la hidrolisis total de la caseína, tal como se puede ver en la Figura 4; mientras que algunas fracciones del primer y

\section{A $280 \mathrm{~nm}$}

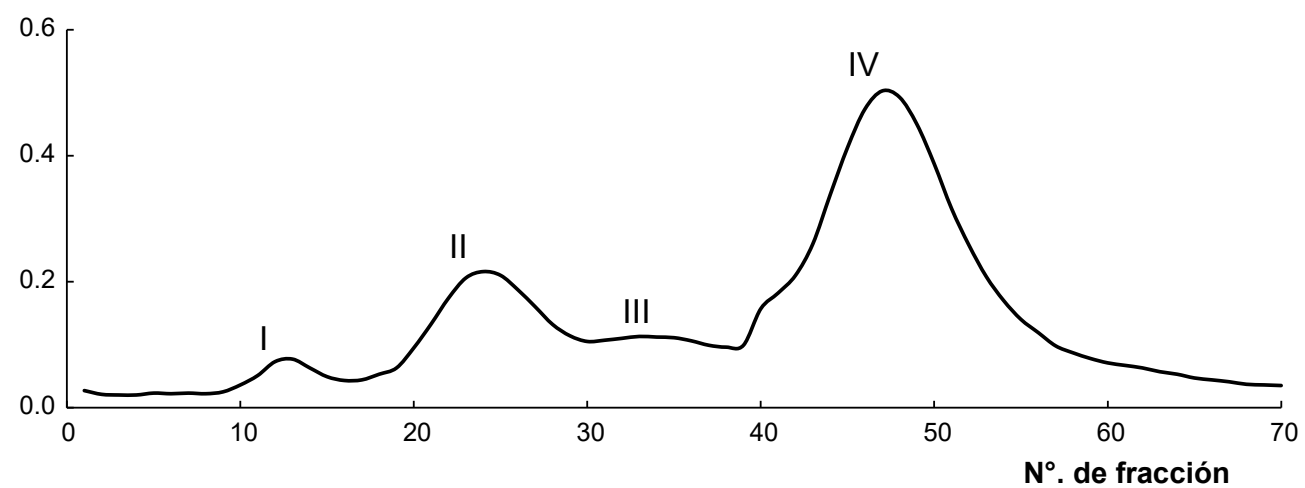

Figura 2. Perfil cromatográfico del veneno soluble de Phymactis papillosa var. rubra-viridis. Se empleó una columna de Sephadex G-50 a pH 7 obteniéndose cuatro picos de proteína (I, II, III y IV). Se colectaron 70 fracciones de $1 \mathrm{~mL}$ con las cuales se ensayaron diferentes actividades. 


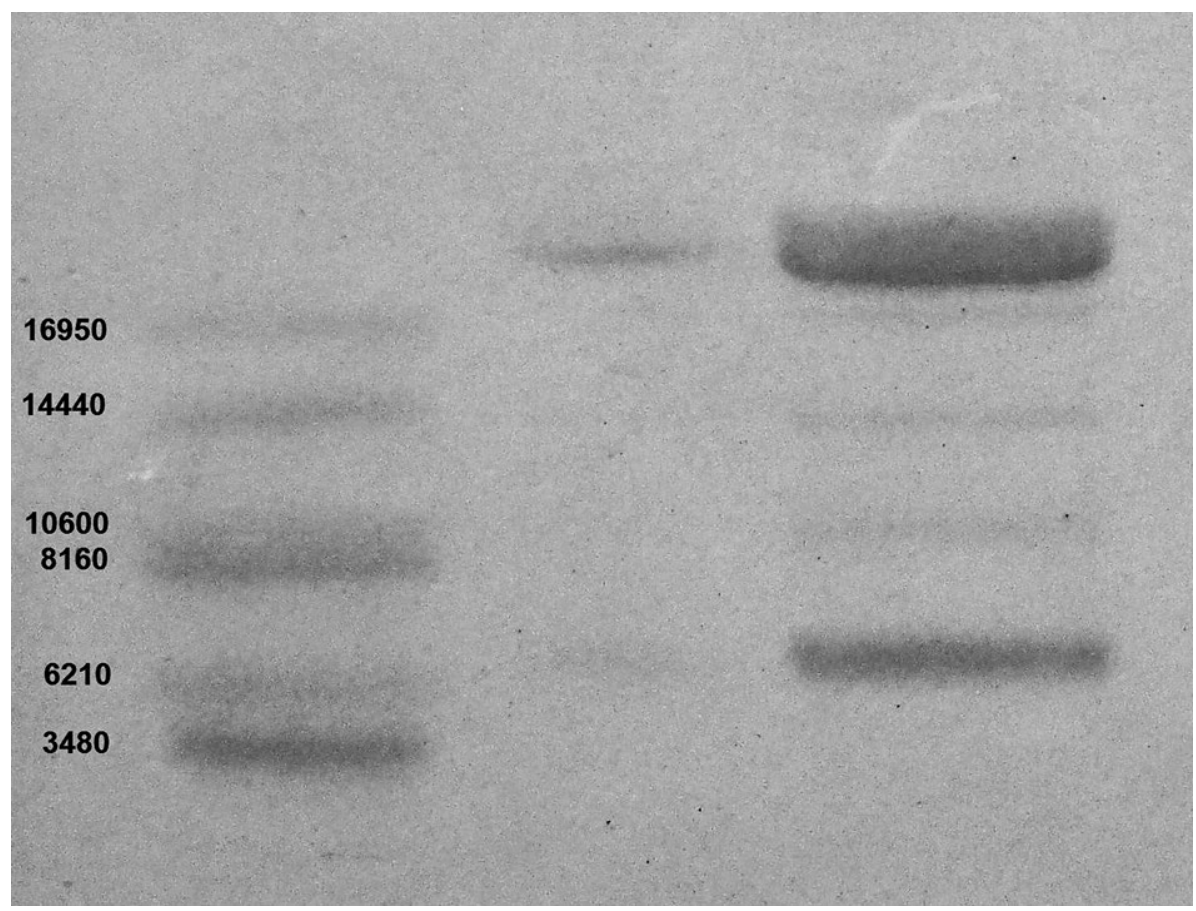

Figura 3. PAGE-SDS del veneno soluble de $P$. papillosa var. rubra-viridis según el método de Shagger \& Von Jagow. En el primer carril se observan las bandas correspondientes a los estándares proteicos utilizados, indicándose el peso molecular de cada uno; en el segundo y tercer carril se tiene el perfil electroforético del veneno soluble con 100 y $670 \mu \mathrm{g}$ de veneno total, respectivamente.

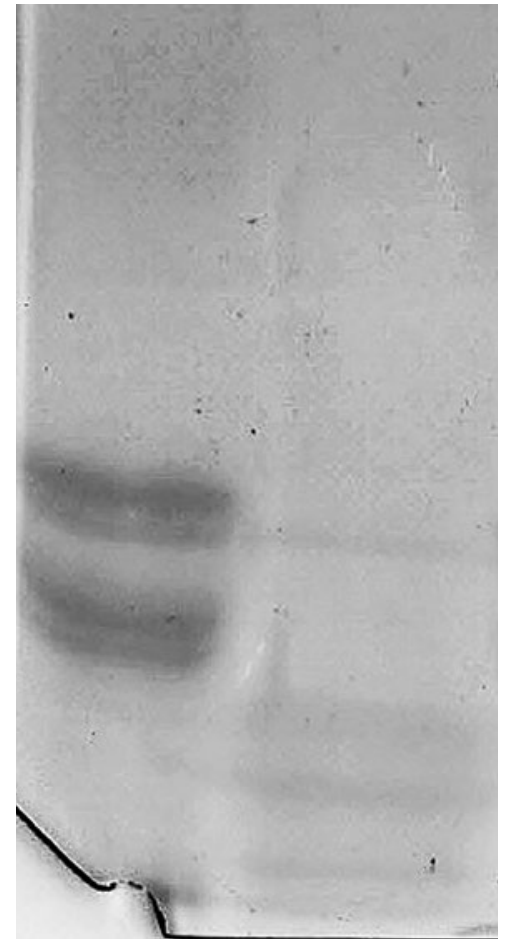

Figura 4. Actividad proteolítica sobre caseína, del veneno soluble de Phymactis papillosa var. rubra-viridis. El patrón electroforético característico de la caseína (carril 1), fue modificado drásticamente luego de ser tratada con el veneno (carril 2).

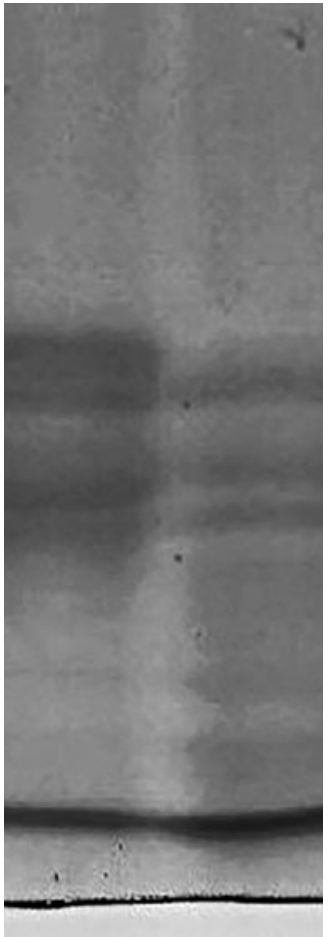

Figura 5. Actividad proteolítica sobre caseína de las fracciones cromatográficas. En el primer carril se muestra el control de caseína, mientras que en el segundo carril se observa un patrón representativo de la hidrolisis parcial de la caseína que se evidenció solo por acción de las fracciones 12, 13 o 33 .

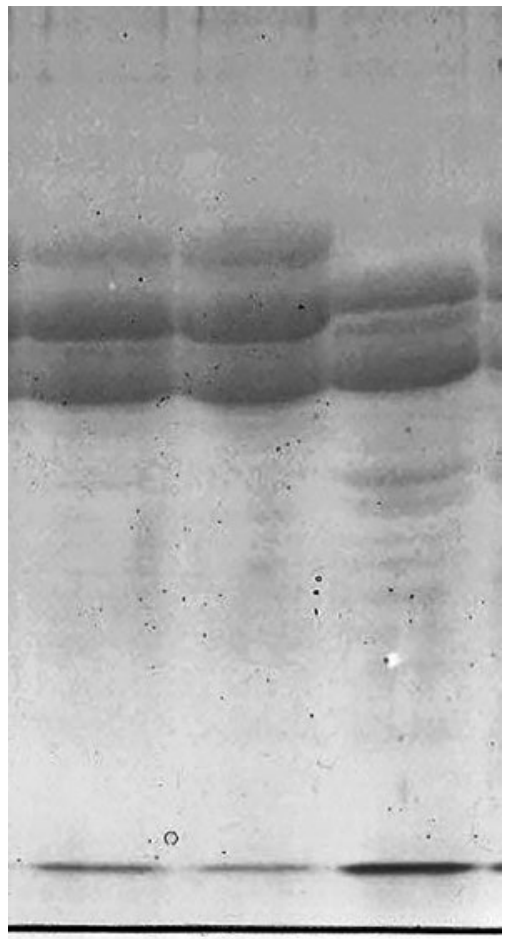

Figura 6. Actividad proteolítica del veneno soluble de Phymactis papillosa var. rubra-viridis sobre fibrinógeno. En el carril del centro se tiene el control de fibrinógeno, mientras que en el carril de la derecha se tiene el fibrinógeno tratado con el veneno soluble; en el primer carril se tiene el fibrinógeno tratado con el veneno preincubado con EDTA. 
tercer pico solo hidrolizaron parcialmente la caseína, tal como se observa en las Figuras 5.

Actividad proteolítica sobre fibrinógeno.- Adicionalmente, se detectó que el veneno soluble también tiene actividad proteolítica sobre fibrinógeno, siendo capaz de hidrolizar las cadenas Aa y $\mathrm{B} \beta$, sin afectar la cadena $\gamma$. El tratamiento del veneno soluble con EDTA, condujo a la pérdida de la actividad proteolítica sobre fibrinógeno. Estos resultados se pueden ver en la Figura 6.

Actividad de fosfolipasa, hialuronidasa, fosfatasa ácida y fosfatasa alcalina.- No se encontraron estas actividades enzimáticas en el veneno soluble de $P$. papillosa.

Actividad hemolítica.- La actividad hemolítica sobre eritrocitos humanos se detectó tanto en el veneno soluble como en las fracciones colectadas correspondientes al pico II. Se determinó que $1.88 \mu \mathrm{g}$ del veneno soluble producen $50 \%$ de hemólisis en 10 minutos. En las fracciones cromatográficas del pico II, los resultados mostraron la presencia de dos picos con actividad hemolítica; uno de ellos, en la subida del pico, y el otro en la caída del mismo. Se determinó que $0.4 \mu \mathrm{g}$ de la primera hemolisina causa $96 \%$ de hemólisis en 10 minutos y que $0.4 \mu \mathrm{g}$ de la segunda hemolisina causa $86 \%$ de hemólisis en 10 minutos.

Toxicidad sobre Mus musculus.- Tanto el veneno soluble (75.4 $\mu \mathrm{g}$ de proteína) como las fracciones del pico III (11 $\mu \mathrm{g}$ de proteína en promedio), mostraron ser tóxicas al ser inyectadas vía intraperitoneal en Mus musculus. Los síntomas que se observaron correspondieron a espasmos en las patas posteriores, luego la parálisis de éstas, salivación, convulsiones e, inmediatamente después, la muerte del animal. Todo esto en un tiempo aproximado de 20 minutos.

\section{Discusión}

Extracción del veneno y cuantificación de proteínas.- Existen hasta cuatro formas de obtener el veneno de los nematocistos de las anémona de mar, sin que existan estudios que demuestren cuál de los métodos es el mejor (Frazao et al. 2012). Una primera forma consiste en utilizar todo el cuerpo del animal, mientras que en una segunda opción se trabaja solo con los tentáculos (Hu et al. 2011) porque éstos concentran la mayor cantidad de nematocistos. Sin embargo, en cualquiera de estas dos formas, se genera mucho material contaminante distinto al procedente de los nematocistos. Las otras dos formas de obtener el veneno de los nematocistos, consiste en tratar a las anémonas con corriente eléctrica (estimulación eléctrica) o someterlas a condiciones hipotónicas (shock hipotónico) lo cual permite obtener un material más limpio (Malpezzi et al. 1993).

Para este estudio, previamente se evaluó la obtención de veneno por estimulación eléctrica y por shock hipotónico (datos no mostrados), y se seleccionó el de shock hipotónico porque generó mayor cantidad de proteína en el veneno.

Nuestros resultados han mostrado que de acuerdo al método de Warburg \& Christian, los $67 \mathrm{mg}$ de veneno obtenidos de 7 ejemplares de $P$. papillosa corresponden a $9.47 \mathrm{mg}$ de proteína, es decir cada ejemplar dio $1.35 \mathrm{mg}$ de proteína en promedio. En algunos trabajos realizados con Stichodactyla helianthus, Bunodosoma granulifera y Phymanthus crucifer, en donde también se utilizó el shock hipotónico para obtener el veneno, se ha encontrado que cada ejemplar expele, respectivamente, 20,3,
39 y 89 mg de proteína (Rodríguez et al. 2012a, Rodríguez et al. 2012b). Esta amplia diferencia en la cantidad de proteína obtenida, podría deberse a particularidades de cada especie de anémona de mar, al estado nutricional o al método de cuantificación utilizado.

Separación cromatográfica de las proteínas del veneno.El perfil cromatográfico en Sephadex G-50 del veneno de $P$ papillosa mostró cuatro picos de proteína que aparecen después del volumen muerto. Esto indicaría que todas las proteínas obtenidas tienen pesos moleculares menores a $30 \mathrm{kDa}$, ya que el Sephadex G-50 puede atrapar proteínas de hasta $30 \mathrm{kDa}$. Estos resultados coinciden en general con lo obtenido en otros venenos de anémonas de mar en donde los principales componentes bioactivos, han mostrado tener pesos moleculares menores a $30 \mathrm{kDa}$. Así por ejemplo, las hemolisinas tienen pesos moleculares entre 10 y $20 \mathrm{kDa}$ (Kem \& Dunn. 1988), las toxinas que afectan los canales de sodio pesan entre 3,5 y 6,5 $\mathrm{kDa}, \mathrm{y}$ las toxinas que bloquean los canales de potasio pesan entre 3 y $5 \mathrm{kDa}$ (Frazao et al. 2012). Igualmente, otros componentes como ShPI-I, un inhibidor de proteasa tipo kunitz de Stichodactyla helianthus, pesa 6.11 kDa (Delfín et al. 1996); la equistatina, un inhibidor de cisteín-proteasas, obtenido de Actinia equina, pesa $13 \mathrm{kDa}$ (Lenarcic et al. 1997) y APETx 1 , un péptido bifuncional de Anthopleura elegantissima pesa 4,55 kDa (Peigneur et al. 2011).

Por estas características el Sephadex G-50 es ampliamente utilizado para separar, preliminarmente, los componentes de los venenos de anemonas de mar, tal como se ha reportado en los casos de Bunodosoma caissarum, Actinia equina, Anthopleura xanthogrammica, Anthopleura fuscoviridis, Urticina crassicornis, Phymanthus crucifer, Bunodosoma granulifera y Stichodactyla helianthus (Malpezzi et al. 1993, Minagawa et al. 2008, Razpotnik et al. 2009, Rodríguez et al. 2012a, Rodríguez et al. 2012b). Sin embargo, la purificación total de cualquier componente de estos venenos, normalmente requiere del uso adicional de otras técnicas cromatográficas como la cromatografía de intercambio iónico, la cromatografía de afinidad y la cromatografía líquida de alta presión (HPLC).

Electroforesis en gel de poliacrilamida con dodecil sulfato de sodio (PAGE-SDS).- Los resultados de la electroforesis de acuerdo al método de Shagger \& Von Jagow del veneno soluble de $P$ papillosa, permitieron determinar que las proteínas de este veneno pesan entre 5 y $25 \mathrm{kDa}$ (Figura 3), lo cual corrobora lo determinado por la cromatografía de filtración.

En aquellos estudios donde se utiliza todo el cuerpo de la anémona de mar, los perfiles electroforéticos muestran también, bandas proteicas con pesos moleculares elevados. Así por ejemplo el patrón electroforético del extracto total de Anthopleura nigrescens tiene proteínas con pesos moleculares de 10 a $200 \mathrm{kDa}$ (Alvarado et al. 2014). En estos casos se considera que las proteínas mayores a $30 \mathrm{kDa}$ pertenecen al cuerpo del animal.

Actividad proteolítica.- En este estudio la actividad proteolítica fue ensayada sobre caseína y su hidrólisis se evaluó por PAGE-SDS. La caseína es una proteína muy utilizada como sustrato para determinar actividad proteolítica de diversas fuentes biológicas, ya que es una proteína particularmente sensible a la acción de muchas proteasas. 
Tal como se describió en resultados, el veneno de $P$. papillosa hidrolizó completamente a la caseína, mientras que en las fracciones cromatográficas la actividad proteolítica se detectó en los picos I y III; sin embargo, en estos casos se observó que la caseína sólo fue hidrolizada parcialmente. Estos resultados indicarían que el veneno total posee al menos dos proteasas y que cada una de ellas hidroliza parcialmente a la caseína, pero cuando están juntas, en el veneno total, producen su completa hidrólisis. Solo en el veneno de la anémona de mar Anthothoe chilensis se ha reportado actividad proteolítica, la cual fue determinada utilizando también caseína (Retuerto et al. 2007), no existiendo otros reportes de proteasas en anémonas de mar. Por otro lado, Moran et al. (2013) han identificado por espectrometría de masas, en proteínas tripsinisadas de nematocistos de Nematostella vectensis, dominios de metalopeptidasa similares a astacina.

Adicionalmente se ensayó la actividad proteolítica del veneno total sobre fibrinógeno. Como es conocido, el fibrinógeno es una proteína plasmática formada por 6 cadenas polipeptídicas ( $2 \mathrm{Aa}, 2 \mathrm{~B} \beta$ y $2 \gamma$ ), que participa en la etapa final de la coagulación sanguínea y que muchas veces es el blanco de acción de ciertas enzimas proteolíticas. Nuestros resultados mostraron que el veneno de $P$. papillosa hidrolizó completamente las cadenas Aa y B $\beta$ del fibrinógeno, pero no la cadena $\gamma$. Las proteasas con acción sobre fibrinógeno también denominadas fibrinogenasas o enzimas fibrinogenolíticas, han sido reportadas ampliamente en venenos de serpientes y de escorpiones (Swenson \& Markland 2005, Brazón et al. 2014), pero no en anémonas de mar, por lo que este hallazgo constituye el primer reporte de ese tipo. La actividad proteolítica que tienen algunos venenos sobre el fibrinógeno, se ha asociado a la capacidad anticoagulante que tiene ese veneno (Brazón et al. 2014). Por otro lado en este estudio también se ha demostrado que el EDTA, un quelante de iones metálicos divalentes como $\mathrm{Ca}^{++}$ y $\mathrm{Mg}^{++}$, inhibe completamente la actividad fibrinogenolítica del veneno de $P$. papillosa, lo que indicaría que este tipo de enzima es una metaloproteasa.

Actividad hemolítica.- Las hemolisinas son toxinas que forman poros en la membrana celular provocando la muerte de la célula. Aquellas que pertenecen a las anémonas de mar se denominan actinoporinas y se caracterizan por tener pesos moleculares alrededor de $20 \mathrm{kDa}$, además de tener afinidad por membranas ricas en esfingomielina y formar poros de $2 \mathrm{~nm}$ de diámetro (Frazao et al. 2012).

En este estudio se ha determinado que el veneno de $P$. papillosa tiene actividad hemolítica sobre eritrocitos humanos $(1.88 \mu \mathrm{g}$ de proteína del veneno producen $50 \%$ de hemólisis en 10 minutos) y que el pico II de proteína de la cromatografía en Sephadex G-50 contiene a su vez dos picos de actividad hemolítica, lo cual indicaría la existencia de dos hemolisinas en este veneno. En otros venenos de anémonas de mar, también se ha reportado la presencia de más de una hemolisina. Por ejemplo en Actinia equina se han detectado tres hemolisinas (Macek \& Lebez. 1988).

La familia actiniidae, a la cual pertenece $P$. papillosa, incluye otras anémonas de mar con venenos que tienen actividad hemolítica, tal como se ha reportado en los casos de Epiactis prolifera y Anthopleura xanthogrammica, donde la actividad hemolítica de ambos venenos puede ser inhibida por esfingomielina (Bernheimer \& Avigad, 1981). Otra anémona de mar de esta familia es Anthopleura asiatica a partir de cuyo veneno se ha aislado una hemolisina denominada bandaporina, la cual pesa $20 \mathrm{kDa}$ y también es inhibida por esfingomielina (Kohno et al. 2009).

Toxicidad sobre Mus musculus.- Nuestros resultados han mostrado que tanto el veneno total de $P$. papillosa $(75.4 \mu \mathrm{g})$ así como las fracciones cromatográficas correspondientes al pico III $(11 \mu \mathrm{g})$ son tóxicas al inyectarse vía intraperitoneal en ratones albinos. Los síntomas observados, antes de que se produzca la muerte del roedor, dejan en evidencia una acción dañina sobre su sistema nervioso, y que por lo tanto el efecto es el resultado de la acción de por lo menos una neurotoxina.

La letalidad de las neurotoxinas puede ser diferente; por ejemplo, en la anémona de mar Bunodoma granulifera se han detectado 2 neurotoxinas denominadas BgII y Bg III que producen toxicidad en ratones albinos a dosis de 0.4 y $21 \mu \mathrm{g} /$ $\mathrm{kg}$, respectivamente (Loret et al. 1994). En la anémona de mar Anthopleura elegantissima se han detectado 3 neurotoxinas denominadas APE 1-1, APE 2-1 y APE5-3 que causan parálisis en el cangrejo Carcinus maenas a dosis de 1,10 y $50 \mu \mathrm{g} / \mathrm{kg}$, respectivamente (Bruhn et al. 2001). Estos datos nos muestran, además, que el veneno de una anémona de mar puede tener varias neurotoxinas. En el caso del veneno estudiado en este trabajo, quizá el efecto neurotóxico también se deba a la acción de más de una neurotoxina.

\section{Litertura citada}

Alvarado J., Y. Álvarez, L. Pedrera, U. Ros, M. Lanio, A. Valle \& C. Âlvarez. 2014. Isolation and partial purification of a hemolytic sphingomyelin-inhibitable fraction from the sea anemone Anthopleura nigrescens. Biotecnología aplicada. 31 (1): 53-56.

Bernheimer A. \& L. Avigad. 1981. New cytolysins in sea anemones from the west coast of the United States. Toxicon. 19(4):529534. DOI https://doi.org/10.1016/0041-0101(81)90011-8

Brazón J., B. Guerrero, G. D’Suze, C. Sevik \& C. Arocha. 2014. Fibrin(ogen)olytic enzymes in scorpion (Tityus discrepans) venom. Comparative Biochemistry and Physiology, Part B. 168:62-69. DOI https://doi.org/10.1016/j. cbpb.2013.11.007

Bruhn T., C. Schaller, C. Schulze, J. Sanchez-Rodrigez, C. Dannmeier, U. Ravens, J. Heubach, K. Eckhardt, J. Schmidtmayer, H. Schmidt, A. Aneiros, E. Wachter \& L. Béress. 2001. Isolation and characterisation of five neurotoxic and cardiotoxic polypeptides from the sea anemone Anthopleura elegantissima. Toxicon. 39 (5):693-702. DOI https://doi.org/10.1016/ S0041-0101(00)00199-9

Crnigoj K., G. Viero, M. Serra, P. Macek \& G. Anderluh. 2009. Molecular mechanism of pore formation by actinoporins. Toxicon. 54: 1125-1134. DOI https://doi.org/10.1016/j. toxicon.2009.02.026

Delfín J., I. Martínez, W. Antuch, V. Morera, Y. González, R. Rodríguez, M. Marquéz, A. Saroyán, N. Larionova, J. Díaz, G. Padrón \& M. Chávez. 1996. Purification, characterization and inmobilization of proteinase inhibitors from Stichodactyla helianthus. Toxicon. 34 (11/12): 1367-1376. DOI https://doi.org/10.1016/S0041-0101(96)00114-6

Di Ferrante N. 1956. Turbidimetric measurement of acid mucopolysaccharides and hyaluronidase activity. Journal of Biological Chemistry. 220: 303-306.

Frazao B., V. Vasconcelos \& A. Antunes. 2012. Sea anemone (Cnidaria, Anthozoa, Actiniaria) toxins: an overview. Marine Drugs. 10: 1812-1851. DOI https://doi.org/10.3390/md10081812

Fuentes F.M., R.A. Mendoza, A.L. Rosales \& R.A. Cisneros. 2008. Guía de manejo y cuidado de animales de laboratorio: ratón. Instituto Nacional de Salud (Perú). Ministerio de Salud, Instituto Nacional de Salud. Lima. Pp 52.

Grotendorst G. \& D. Hessinger. 1999. Purification and partial characterization of the phospholipase A2 and co-lytic factor from sea anemone (Aiptasia pallida) nematocyst venom. Toxicon. 37(12): 1779-1796. DOI https://doi.org/10.1016/ S0041-0101(99)00120-8 
Haussermann V. 2004. Re-description of Phymactis papillosa (Lesson, 1830) and Phymanthea pluvia (Drayton in Dana, 1846) (Cnidaria: Anthozoa), two common actiniid sea anemones from the south east Pacific with a discussion of related genera. Zoologische Mededelingen 78. http://www.repository. naturalis.nl/document $/ 43183$

Hu B., W. Guo, L. Wang, J. Wang, X. Liu \& B. Jiao. 2011. Purification and characterization of gigantoxin- 4 , a new actinoporin from the sea anemone Stichodactyla gigantea. International Journal of Biological Sciences. 7(6): 729-739. DOI https:// doi.org/10.7150/ijbs.7.729

Jouiaei M., A. Yanagihara, B. Madio, T. Nevalainen, P. Alewood \& B. Fry. 2015. Ancient Venom Systems: A Review on Cnidaria Toxins. Toxins. 7: 2251-2271. DOI https://doi. org/10.3390/toxins 7062251

Kem W. \& B. Dunn. 1988. Separation and characterization of four different aminoacid sequence variants of a sea anemone (Stichodactyla helianthus) protein cytolysin. Toxicon. 26 (11): 997-1008. DOI https://doi.org/10.1016/00410101(88)90198-5

Kohno Y., H. Satoh, A. Iguchi \& H. Nagai. 2009. Characterization of a new hemolytic protein toxin from the sea anemone Anthopleura asiatica. Fisheries Science. 75 (4): 1049-1054. DOI https://doi.org/10.1007/s12562-009-0112-2

Laemmli U. K. 1970. Cleavage of structurals proteins during the assembly of the head of bacteriophage T4. Nature. 227: 680-685. DOI https://doi.org/10.1038/227680a0

Landucci E., Q. Dias, F. Marangoni, A. Vilca-Quispe, J. ValerianoZapana, F. Torres-Huaco, D. Martins-de-Souza, S. Marangoni \& L. Ponce-Soto. 2012. Purification and inflammatory edema induced by two PLA2 (Anch TX-I and Anch TX-II) from sea anemone Anthothoe chilensis (Actiniaria: Sagartiidae). Comp. Biochem. Physiol. B 161: 170-7. DOI https:// doi.org/10.1016/j.cbpb.2011.11.003

Lenarcic B., A. Ritonja, B. Strukelj, B. Turk \& V. Turk. 1997. Equistatin, a new inhibitor of cysteine proteinases from Actinia equina, is structurally related to Thyroglobulin type- 1 domain. The Journal of Biological Chemistry. 272(21):1389913903. DOI https://doi.org/10.1074/jbc.272.21.13899

Loret E., R. Menendez, P. Mansuelle, F. Sampieri \& H. Rochat. 1994. Positively charged amino acid residues located similarly in sea anemone and scorpion toxins. Journal of Biological Chemistry. 269(24): 16785-16788.

Macek P. \& D. Lebez. 1988. Isolation and characterization of three lethal and hemolytic toxins from the sea anemone Actinia equina L. Toxicon. 26(5): 441-451. DOI https://doi. org/10.1016/0041-0101(88)90183-3

Malpezzi E., J. De Freitas, K. Muramoto \& H. Kamiya. 1993. Characterization of peptides in sea anemone venom collected by a novel procedure. Toxicon. 31(7): 853-864. DOI https:// doi.org/10.1016/0041-0101(93)90220-D

Marinetti G. 1965. The action of phospholipase A on lipoproteins. Biochimica et Biophysica Acta. 98: 554-565. DOI https:// doi.org/10.1016/0005-2760(65)90152-9
Minagawa S., M. Sugiyama, M. Ishida, Y. Nagashima \& K. Shiomi. 2008. Kunitz-type protease inhibitors from acrorhagi of three species of sea anemones. Comparative Biochemistry and Physiology, Part B. 150: 240-245. DOI https://doi. org/10.1016/j.cbpb.2008.03.010

Moran Y., D. Praher, A. Schlesinger, A. Ayalon, Y. Tal \& U. Technau. 2013. Analysis of soluble protein contents from the nematocysts of a model sea anemone sheds light on venom evolution. Marine Biotechnology. 15: 329-339. DOI https:// doi.org/10.1007/s10126-012-9491-y

Peigneur S., B. Billen, R. Derua, E. Waelkens, S. Debaveye, L. Béress \&J. Tytgat. 2011. A bifunctional sea anemone peptide with Kunitz type protease and potassium channel inhibiting properties. Biochemical Pharmacology. 82 (1): 81-90. DOI https://doi.org/10.1016/j.bcp.2011.03.023

Razpotnik A., I. Krizaj, W. Kem, P. Macek \& T. Turk. 2009. A new cytolytic protein from the sea anemone Urticina crassicornis that binds to cholesterol- and sphingomyelin-rich membranes. Toxicon. 53: 762-769. DOI https://doi.org/10.1016/j. toxicon.2009.02.007

Retuerto F., E. Arbaiza, Y. Quiroz-Garrido, R. Estrada \& J. Zavala. 2007. Actividad biológica del veneno de Anthothoe chilensis (Lesson, 1830) (Actiniaria: Sagartiidae). Revista Peruana de Biología. 14(2): 277-282. DOI http://dx.doi.org/10.15381/ rpb.v14i2.1800

Rodríguez A., J. Silva, F. Sac, Z. Qiang, J. de Freitas, A. Pimenta, M. de Lima, K. Konno, S. Yuen, A. Garateix \& A. Zaharenko. 2012a. Peptide fingerprinting of the neurotoxic fractions isolated from the secretions of sea anemones Stichodactyla helianthus and Bunodosoma granulifera. New members of the APETx-like family identified by a 454 pyrosequencing approach. Peptides. 34:26-38. DOI https://doi. org/10.1016/j.peptides.2011.10.011

Rodríguez A., L. Standker, A. Zaharenko, A. Garateix, W. Forssmann, L. Béress, O. Valdés, Y. Hernández \& A. Laguna. 2012b. Combining multidimensional liquid chromatography and MALDI-TOF-MS for the fingerprint analysis of secreted peptides from the unexplored sea anemone species Phymanthus crucifer. Journal of Chromatography B. 903:30-39. DOI https://doi.org/10.1016/j.jchromb.2012.06.034

Schagger H. \& von Jagow, G., 1987. Tricine-sodium dodecyl sulfatepolyacrylamide gel electrophoresis for the separation of proteins in the range from 1 to $100 \mathrm{kDa}$. Anal. Biochem. 166 (2): 368-379. DOI https://doi.org/10.1016/00032697(87)90587-2

Swenson S. \& F. Markland. 2005. Snake venom fibrin(ogen)olytic enzymes. Toxicon 45 (8): 1021-39. DOI https://doi. org/10.1016/j.toxicon.2005.02.027

Torres-Larios, A., G. Gurrola, F. Zamudio \& L. Possani. 2000. Hadrurin, a new antimicrobial peptide from the venom of the scorpion Hadrurus aztecus. European Journal of Biochemistry. 267: 5023-5031. DOI https://doi.org/10.1046/j.14321327.2000.01556.x

Warburg O. \& W. Christian. 1941. Isolierung und kristallisation der garungs ferments enolase. Biochem Z. 310: 384-421. 
